\title{
عزل وتثخيص البكتريا الملوثة لنهر دجلة في بعض أقضية محافظة واسط
}

\section{Isolation and Identification of the Bacteria which Contaminated the Tigris River in Some Districts of Wasit Province}

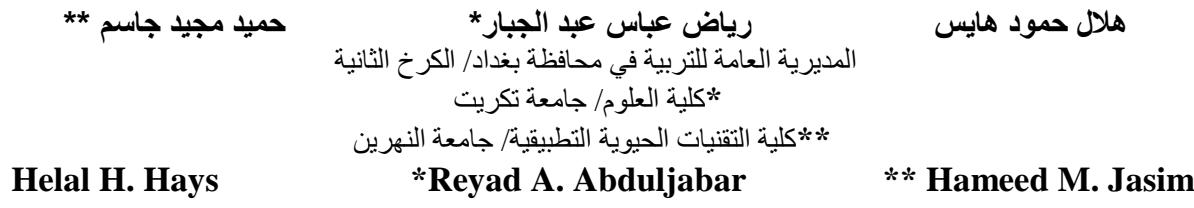

\author{
General Directorate for Educational in Baghdad/ Karkh 2 \\ *University of Tikrit/ College of Sciences \\ **AL-Nauhraein University/ College of Applied Biotechnology
}

helalalhamood@yahoo.com

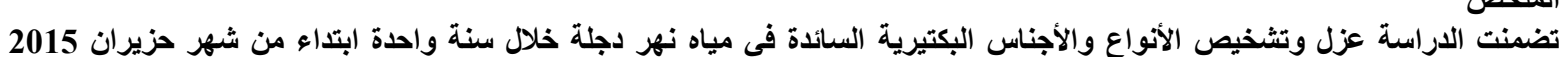

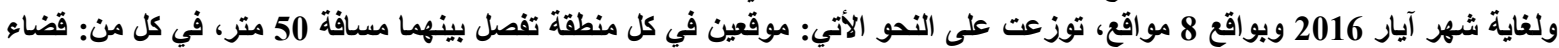

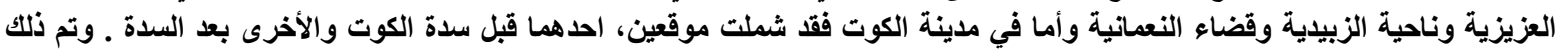

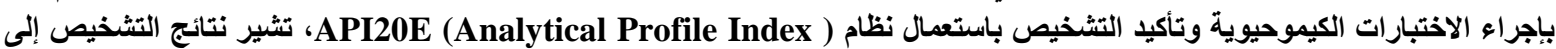
وجود 22 عزلة عائدة للأجناس والأنواع الآتية في عينات مياه النها Aeromnonas veronii و و و Aeromonas punctata و و Aeromonas caviae 9 Enterobacter cloacae و Pseudomonas alcaligenes و Exiguobacterium profoun و و و Aeromonas hydrophila و Photobacterium damala g Bordetella spp و Pseudomonas fluroescen و و Shigella spp و Buttiaxella agrestis و Moraxella spp و Serratia liquefciens و Acinetobacter bumannii Enterobacterium و Escherichia coli grwinia spp و Pasteurella spp و Chryseomonas meningosept hormaechei

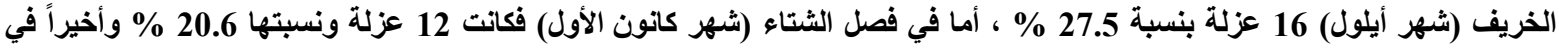

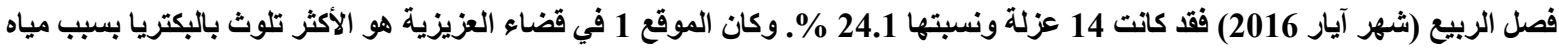
المجاري المنزلية وفضلات المواشي ضمن الأنثطة الزراعية.

الكلمات الففتاحية: بكتبريولوجية، كيموحيوية، نهر دجلة، واسط
\end{abstract}

Abstract

The bacteriological study was included isolation and identification aquatic bacteria of dominant species in Tigris River. The period of the study for one year which starting from June 2015 until 2016 May which include 8 stations which distributed as follows : two station in the each site with space 50-meter between them, which have all of the following districts counties run through AL-Azizia AL- Zubaydiah, AL-Numaniyah and AL-Akut distributed as two repeaters within Wasit province. Identifications methods using the biochemical tests and verify the identification by API20E system. Results have pointed to the appearance of the isolation of 22 belonging to the following genera and species in the river water samples involve: Aeromnonas veronii, Aeromonas punctata, Bacillus subtilis, Exiguobacterium profoun, Pseudomonas alcaligenes, Enterobacter cloacae, Aeromonas caviae, Pseudomonas fluroescen, Bordetella spp, Photobacterium damala, Aeromonas hydrophila, Acinetobacter bumannii, Serratia liquefciens, Moraxella spp, Buttiaxella agrestis, Shigella spp, Chryseomonas meningosept, Pasteurella spp , Erwinia spp , Escherichia coli, Enterobacterium hormaechei, and Escherichia vuleneris. Temporal variation of aquatic bacteria in the study area was include: 16 bacterial isolate at June $2015(27.5 \%) 16$ isolate at September (27.5\%), 12 isolate at December (20.6 \%) and 14 isolate in the May 2016 (24.1\%). This study discover that station 1 was the most contaminated because domestic sewage and cattle feces within agricultural activities.

Key Words: Bacteriology, Biochemical, Tigris, Wasit

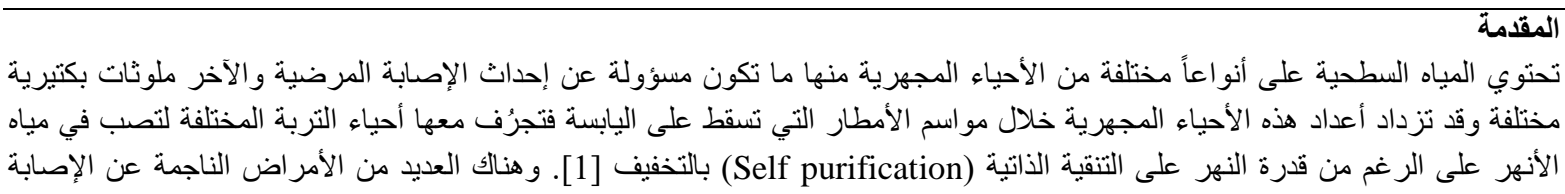


بالأحياء المجهرية التي مصدرها الماء (Waterborne disease) كالتايفوئيد والكولير اوالزحار البكتيري والاميبي والالتهاب المعوي و التهاب

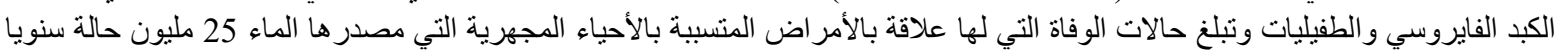

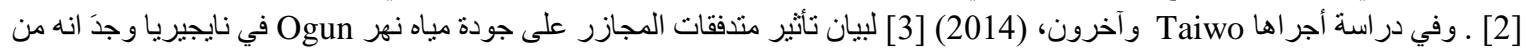

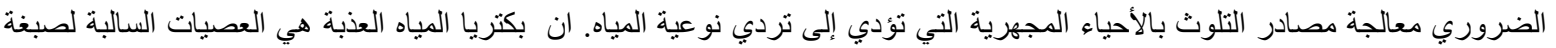

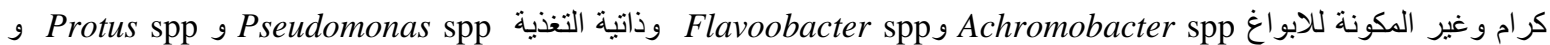

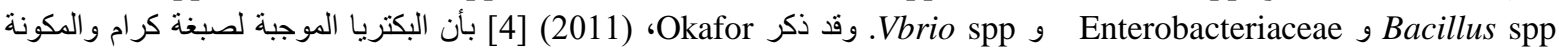

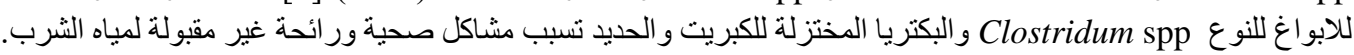

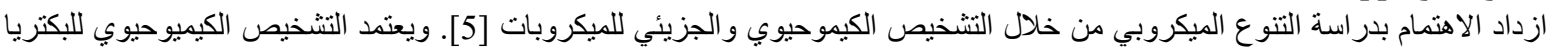

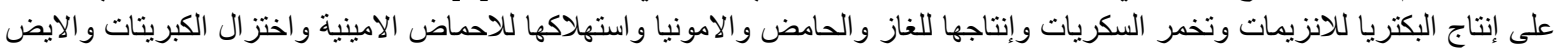

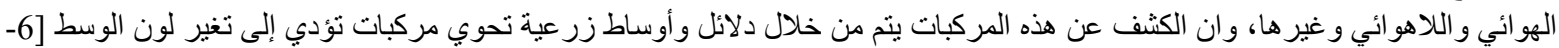

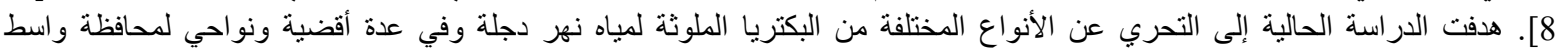

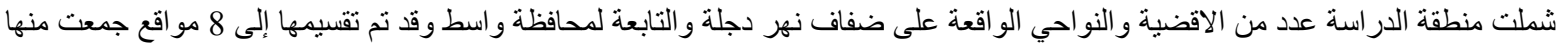

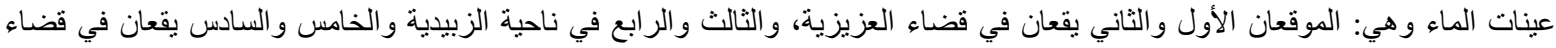

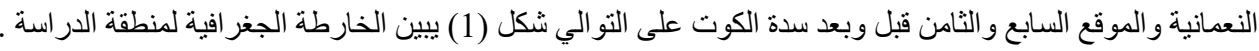

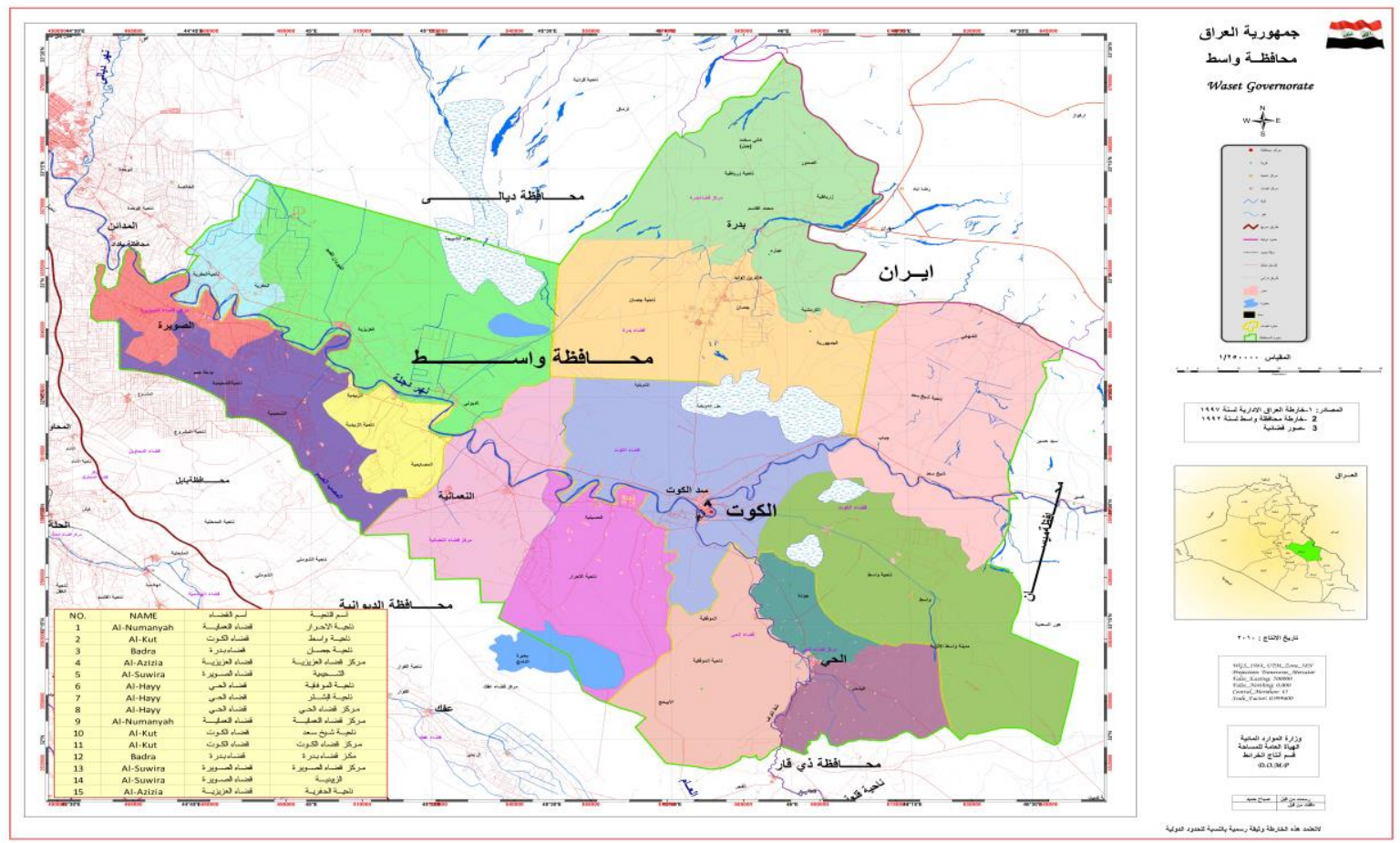

شكل (1): الخارطة الجغرافية لاقضية ونواحي محافظة واسط التي جمعت منها عينات الاراسة

جمع العينات

جمعت عينات الماء من جميع محطات الدراسة اعتبار امن حزيران 2015 ولغاية ايار 2016 وبمعدل عينة وبمكررين من كل موقع ولكل فصل.

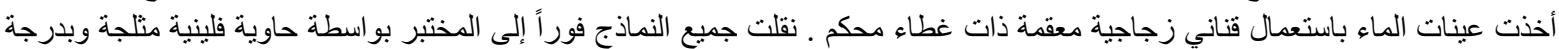

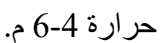
التشخيص البكتريولوجي

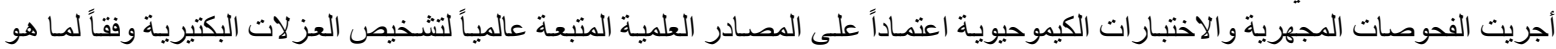

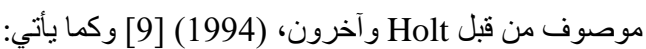

الصفات المظهرية

حددت الصفات المظهرية لعز لات البكتريا إعتماداً على لون المستعمر ات وشكاتها على الأوساط الزرعية التفريقية وشبه الانتقائية (وسط آكار

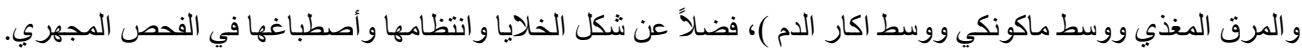

أجريت جميع الاختبارات الكيموحيوية لتثخيص العز لات البكتيرية وفقاً لما هو موصوف من قبل Atlas وآخرون (1995) [10] وكما يأتي : 
إختبار إنزيم الكاتليز وإختبار الأوكسديز وإختبار الجيلاتينيز وإختبار أحمر المثيل وإختبار فوكس - بروسكاور وإختبار تخمر السكريات واختبار الحركة.

التشخيص باستخدام العدة التشخيصية API 20E (المجهز من شركة Biomerieux)

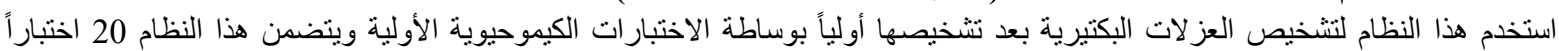
كيموحيوياً لتشخيص العز لات التخام البكتيرية. النتائج والمناقشة

أجريت عملية تنمية العز لات البكتيرية لعينات المياه المأخوذة من أقضية ونو احي محافظة واسط على الأوساط الزر عية الغنية للتعرف على أعداد

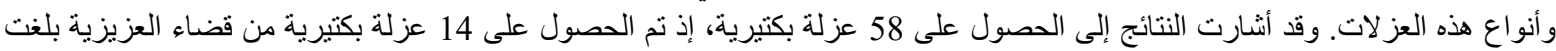

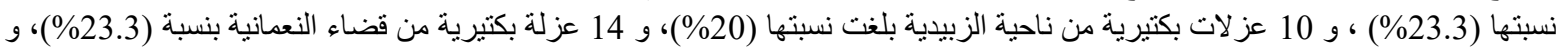

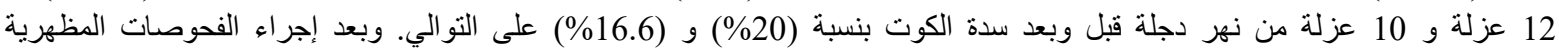

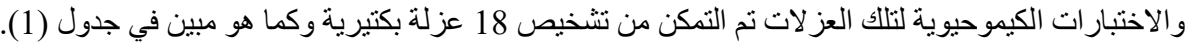

جدول (1): التشخيص الكيموحيوي للعزلات البكتيرية باستخدام العدة التشخيصية API20E الاختبار

\begin{tabular}{|c|c|c|c|c|c|c|c|c|c|c|c|c|c|c|c|c|c|c|c|c|}
\hline 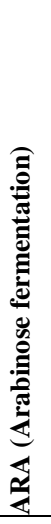 & 昰 & 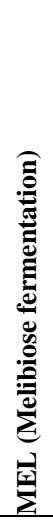 & 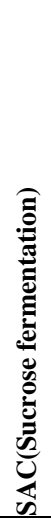 & 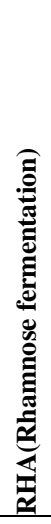 & 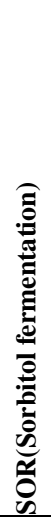 & 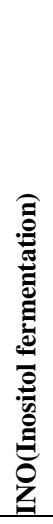 & 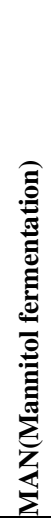 & 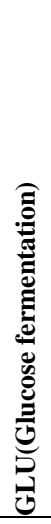 & 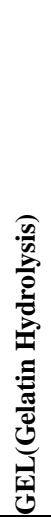 & 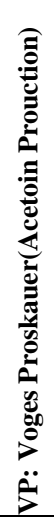 & 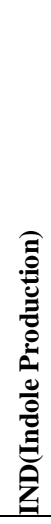 & 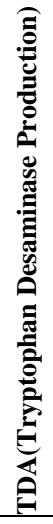 & 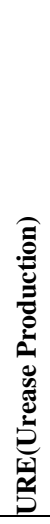 & 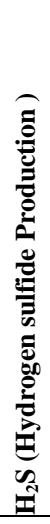 & 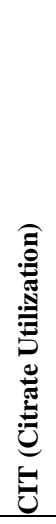 & 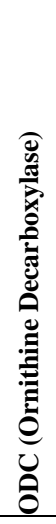 & 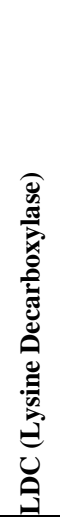 & 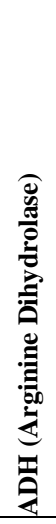 & 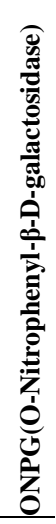 & البكتريا \\
\hline - & - & - & + & - & - & - & + & + & + & - & + & - & - & - & + & - & + & + & + & $\begin{array}{l}\text { Aeromonas } \\
\text { hydrophila }\end{array}$ \\
\hline+ & + & + & + & + & + & + & + & + & + & + & + & - & - & - & + & + & - & + & + & $\begin{array}{c}\text { Enterobacter } \\
\text { cloacae }\end{array}$ \\
\hline - & - & - & - & - & - & - & - & - & - & - & - & - & - & - & + & - & - & + & - & $\begin{array}{c}\text { Pseudomonas } \\
\text { fluroescens }\end{array}$ \\
\hline - & - & - & - & - & - & - & - & - & - & - & - & - & - & - & + & - & - & - & - & Bordetella spp \\
\hline - & - & - & + & - & - & - & - & + & - & - & - & - & + & - & - & - & - & + & - & $\begin{array}{c}\text { Photobacteriu } \\
\text { m damala }\end{array}$ \\
\hline - & - & - & + & - & - & - & + & + & + & - & + & - & - & - & + & - & + & + & + & $\begin{array}{c}\text { Acinetobacter } \\
\text { bumannii }\end{array}$ \\
\hline+ & + & + & + & + & + & + & + & + & + & - & - & - & - & - & + & + & + & + & + & $\begin{array}{c}\text { Serratia } \\
\text { liquefciens }\end{array}$ \\
\hline - & - & - & - & - & - & - & - & - & - & - & - & - & - & - & + & - & - & + & - & Moraxella spp \\
\hline+ & + & - & - & + & - & - & + & + & - & - & - & - & - & - & + & - & - & - & + & $\begin{array}{c}\text { Buttiaxella } \\
\text { agrestis }\end{array}$ \\
\hline- & + & - & + & - & - & - & + & - & - & - & - & - & - & - & - & - & - & - & + & Shigella spp \\
\hline - & - & - & - & - & - & - & - & - & + & + & - & - & - & - & - & - & - & - & + & $\begin{array}{l}\text { Chryseomonas } \\
\text { meningosept }\end{array}$ \\
\hline - & - & - & - & - & + & - & - & - & - & - & - & - & - & - & - & - & - & - & - & $\begin{array}{c}\text { Pasteurella } \\
\text { spp }\end{array}$ \\
\hline+ & + & - & + & - & - & - & + & + & - & - & + & - & - & - & + & - & - & - & + & Erwinia spp \\
\hline+ & - & + & + & + & + & - & + & + & - & - & + & - & - & - & - & + & + & + & + & $\begin{array}{c}\text { Escherichia } \\
\text { coli }\end{array}$ \\
\hline+ & - & + & + & + & + & - & + & + & - & - & + & - & - & - & - & + & + & + & + & $\begin{array}{c}\text { Escherichia } \\
\text { vuleneris }\end{array}$ \\
\hline - & - & - & - & - & - & - & - & - & + & - & - & - & - & - & - & - & - & - & - & $\begin{array}{c}\text { Burkholderia } \\
\text { cepacia }\end{array}$ \\
\hline+ & + & + & + & + & + & + & + & - & - & + & + & - & + & - & + & - & - & - & + & $\begin{array}{c}\text { Klebsiella } \\
\text { oxytoca }\end{array}$ \\
\hline - & - & - & - & - & - & - & - & + & - & - & + & + & + & - & + & + & - & - & - & $\begin{array}{c}\text { Morganella } \\
\text { morganii }\end{array}$ \\
\hline
\end{tabular}


من ناحية أخرى فانه لا يوجد تباين زماني في ظهور البكتريا المعزولة إذ تم عزل وتشخيص 16 عزلة في فصل الصيف كما مبين في جدول

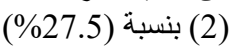

جلول (2) : الأنواع والأجناس البكتيرية المعزولة من مياه نهر دجلة ضمن محافظة واسط لفصل الصيف (شهر حزيران للعام 2015)

\begin{tabular}{|c|c|c|c|c|c|c|}
\hline \multicolumn{5}{|c|}{ حزيران 2015} & \multirow[b]{2}{*}{ الأجناس والأنواع البكتيرية السائدة في المياه } & \multirow[b]{2}{*}{$ت$} \\
\hline 畓哥 & 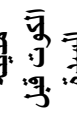 & 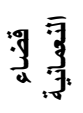 & 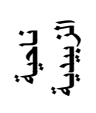 & 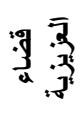 & & \\
\hline 1 & 1 & 1 & - & 1 & Aeromnonas veronii & 1 \\
\hline - & - & - & 1 & 1 & Exiguobacterium profoun & 2 \\
\hline 1 & - & - & - & 1 & Pseudomonas alcaligenes & 3 \\
\hline- & 1 & 1 & - & 1 & Enterobacter cloacae & 4 \\
\hline- & - & - & 1 & - & Aeromonas caviae & 5 \\
\hline- & - & - & 1 & - & Pseudomonas fluroescens & 6 \\
\hline- & 1 & - & - & - & Bordetella spp & 7 \\
\hline- & 1 & - & - & - & Photobacterium damala & 8 \\
\hline- & 1 & - & - & - & Aeromonas hydrophila & 9 \\
\hline
\end{tabular}

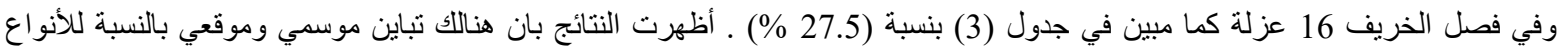

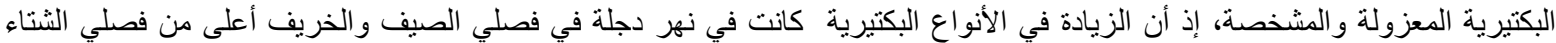

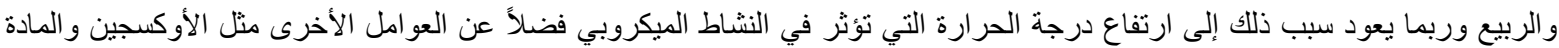

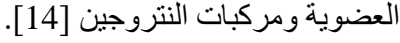

جدول (3): الأنواع والأجناس البكتيرية المعزولة من مياه نهر دجلة ضمن محافظة واسط لفصل الخريف (شهر أيلول للعام 2015)

\begin{tabular}{|c|c|c|c|c|c|c|}
\hline \multicolumn{5}{|c|}{ أيلول 2015} & \multirow[b]{2}{*}{ الأجناس والأنواع البكتيرية السائدة في المياه } & \multirow[b]{2}{*}{$ت$} \\
\hline 录哥哥 & & & & : & & \\
\hline 1 & 1 & 1 & 1 & 1 & Aeromnonas veronii & 1 \\
\hline - & - & 1 & - & - & Aeromonas punctata & 2 \\
\hline 1 & 1 & - & - & - & Bacillus subtilis & 3 \\
\hline 1 & 1 & 1 & 1 & 1 & Pseudomonas alcaligenes & 4 \\
\hline- & - & 1 & - & - & Acinetobacter baumannii & 5 \\
\hline - & - & 1 & - & - & Serratia liquefciens & 6 \\
\hline 1 & - & - & - & - & Buttiaxella agrestis & 7 \\
\hline
\end{tabular}

تتفق هذه النتائج مع تلك التي حصل عليها شبيب، (2013) [13] عند دراسته لدلائل التلوث الميكروبي لنهر دجلة في قضاء النعمانية ضمن محافظة واسط و أما في فصل الثتاء فكانت 14 عزلة كما مبين في جدول (4) ونسبتها (20.6\%).

جدول (4): الأنواع والأجناس البكتيرية المعزولة من مياه نهر دجلة ضمن محافظة واسط لفصل الثتاء (شهر كانون الأول للعام 2015)

\begin{tabular}{|c|c|c|c|c|c|c|}
\hline \multicolumn{5}{|c|}{ كانون الاول 2015} & \multirow[b]{2}{*}{ الأجناس والأنواع البكتيرية السائدة في المياه } & \\
\hline 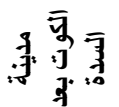 & 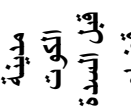 & 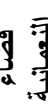 & ב. & $\frac{7}{4}$ & & $ت$ \\
\hline- & 1 & 1 & 1 & 1 & Aeromonas punctata & 1 \\
\hline 1 & 1 & 1 & 1 & 1 & Pseudomonas alcaligenes & 2 \\
\hline - & - & 1 & - & - & Aeromonas hydrophila & 3 \\
\hline - & - & - & 1 & - & Buttiaxella agrestis & 4 \\
\hline - & - & 1 & - & - & Shigella spp & 5 \\
\hline 1 & - & - & - & - & Chryseomonas meningosept & 6 \\
\hline - & - & - & - & 1 & Escherichia coli & 7 \\
\hline
\end{tabular}


وأخير اً في فصل الربيع فقد كانت 12 عزلة كما مبين في جدول (5) ونسبتها (24.1\%) .

جدول (5): الأنواع والأجناس البكتيرية المعزولة من مياه نهر دجلة ضمن محافظة واسط لفصل الربيع (شهر آذار للعام 2016) اذار 2016

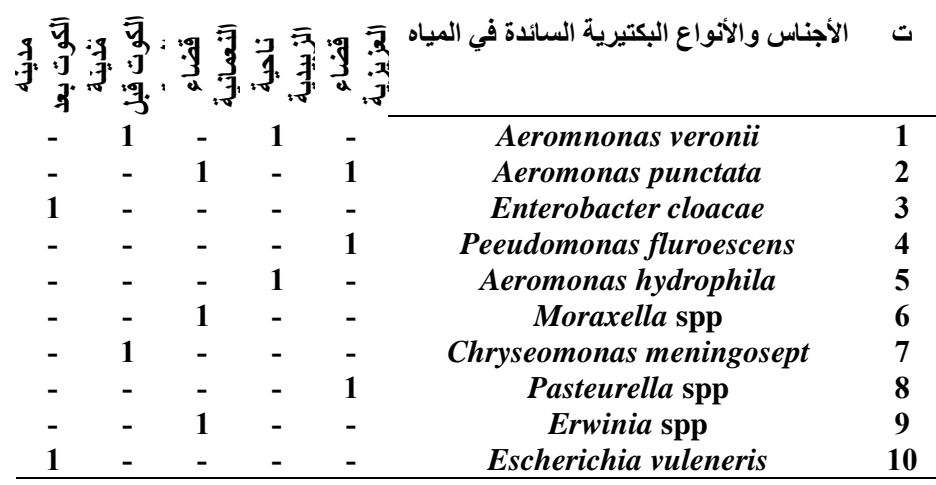

أظهرت النتائج بان هنالك تباين موسمي وموقعي بالنسبة للأنواع البكتيرية المعزولة والمشخصة إذ كانت في نهر دجلة في فصلي الصيف

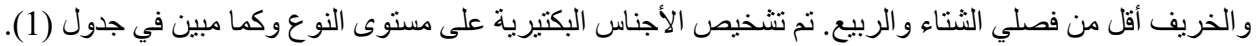

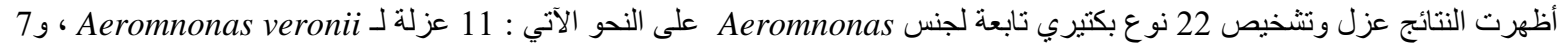

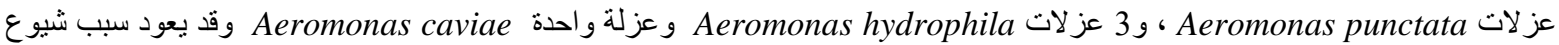
انتشار هذه الأنواع التابعة لجنس Aeromnonas spp في مياه النهر لكونها منوطنة (autochthonous) في البيئات المائية (

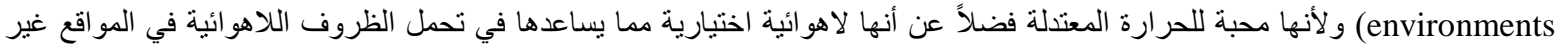

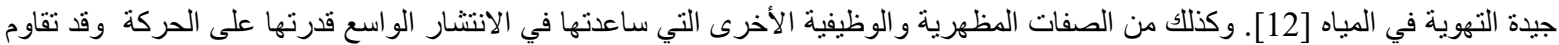

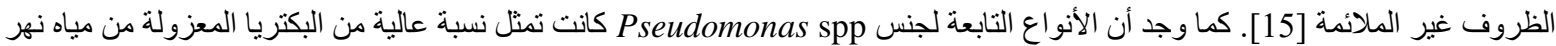

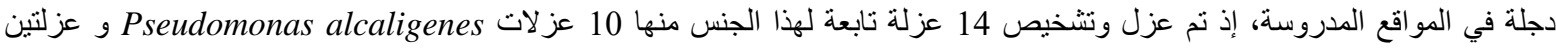
Pseudomonas luteola (Chryseomonas meningosept) و كانت نتائج الأعداد اقل مما

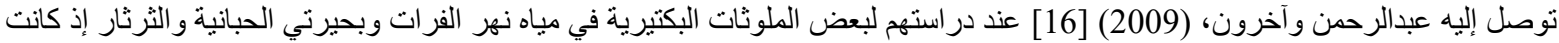

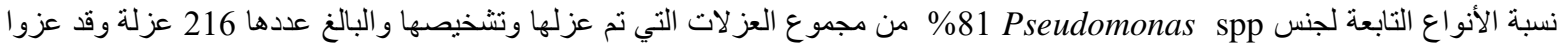

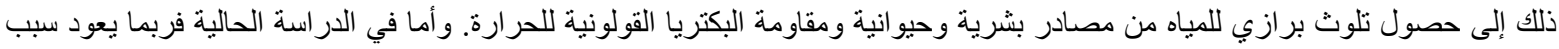

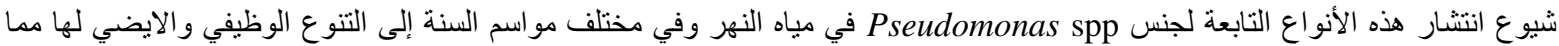

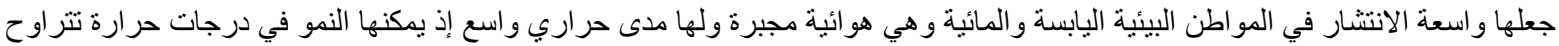

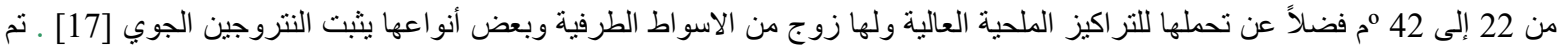

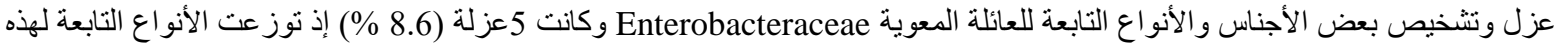

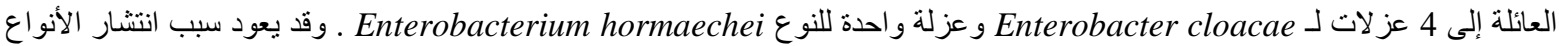
التابعة لجنس Enterobacter spp في مياه النهر و على مختلف مواسم السنة إلى كونها احد الأنواع التي تنمو في درجات حر ارة مياه معتدلة [18] [. كما تشير النتائج الى ظهور عزلتين لبكتريا Buttiaxella agrestis في مياه نهر دجلة في المحطات

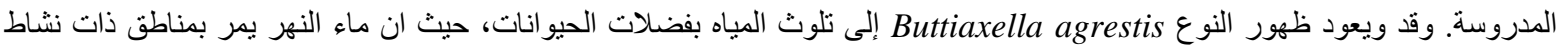

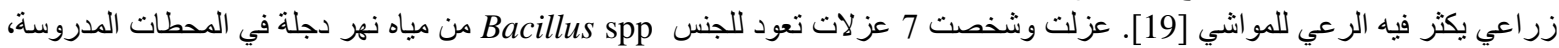

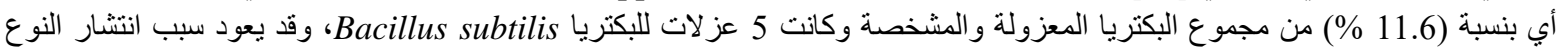
Bacillus subtilis

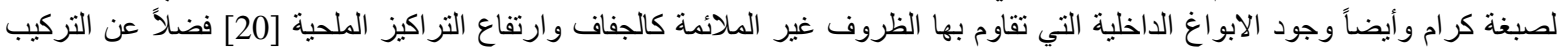

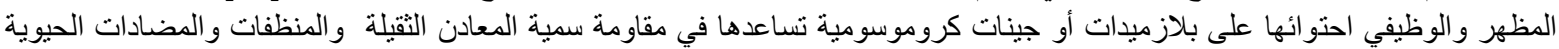

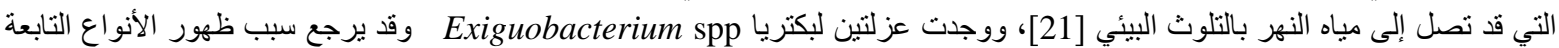

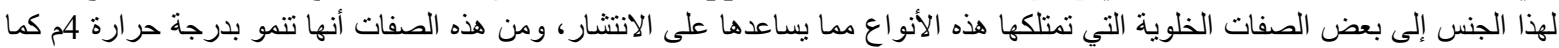

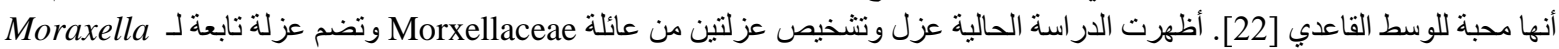

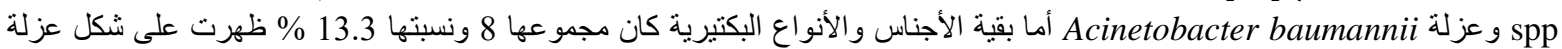
واحدة هي كل من الاجناس و الأنو اع البكتيرية الآتية : Bordetella spp و و Masteurella spp و و

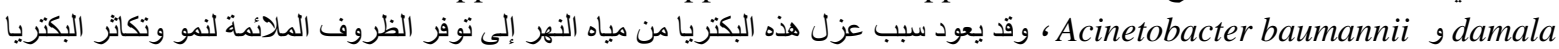

في حالة تو افر المغذيات [4] الاستنتاجات

ملائمة مياه نهر دجلة ضمن منطقة الدر اسة لسيادة الأنو اع البكتيرية التابعة لجنس Aeromonas spp إذ كانت الأكثر سيادة . 
إن أجناس البكتريا السائدة في مياه نهر دجلة ضمن أقضية محافظة واسط هي كل من Aeromnonas spp و Pseudomonas spp و

Bacillus spp و Enterobacteraceae

إن التغاير في أنواع أجناس العزلات البكتيرية من محطة لأخرى يعود إلى اختلاف مصادر التلوث، و الى الظروف البيئية التي تتعرض لها المو اقع كافة خلال فصول السنة. أنوائ.

1. Sethi, P. and Kulkarni. (2010). Environmental Microbiology. Alfa Publication, New Delhi, India: p 296.

2. Cunningham, William P. and Cunningham, Mary. (2006). Environmental Science Inquiry and Applications. Third Edition. McGraw-Hill Companies. New York. Inc. USA. pp 428.

3. Taiwo, A.G., Adewunmi, A.R., Ajayi, J.O., Oseni, O.A. and Lyanda, Lanner, Y.A. (2014). PhysicoChemical and Microbial Analysis of the Impact of Abatoir Effluent on Ogun River Course. Int. J. Chem. Technol. Res. 6(5): pp 3083-3090.

4. Okafor, N. (2011). Environmental Microbiology of Aquatic and Water System. Springer Dordrecht Heidelberg London New York Springer Science and Business Media B.V. pp: 307

5. Zeglin, L.H. (2015). Stream Microbial Response to Environmental Changes: review and synthesis of existing research. Front. Microb. 6 (454): 1-15.

6. Hemraj, Vashit, Dikisha, Shama and Avneet, Gupta. (2013). A Review on a Commonly Used Biochemical Test for Bacteria. Int. J. Life. Sci. 1 (1): 1-7

7. Dilnessa, T., Demeke, Gebresilasie, Mengistu, Getachew and Bitew, Adane. (2016). Emerging Blood Culture Technologies for Isolation of Blood Pathogens at Clinical Microbiology Laboratories, Review Article. J. Med. Microb. and Diagn. 5 (2): 1-7.

8. Robinson, A.; McCcarter Yrette S. and Tetreault, Janice. (1995). Comparison of Crystal Etric/Nonferminter System, API20 E System and Vitek Automicrobic System for Identification of Gram-Negative Bacilli. J. Clin. Microbiol. 33 (1): 364-370.

9. Holt, J.G., Krieg, N.R., Sneath, H.A. Staley, J.T. and Williams, S.T. (1994). Berg's Manual of Determinative Bacteriology. (9 ${ }^{\text {th }}$ ed.). Williams and Wilkins. U.S.A. Pp: 479-484.

10. Atlas, R.M., Parks, L.C. and Brown, A.E. (1995). Labroatory Manual of Experimental Microbiology, Mosby- year book, Inc, USA.

11. Igbinosa, Isoken H., Igumbor, Ehimario, U. and Aghdasi, Farhad. (2012). Emerging Aeromonas Species Infections and Their Significance in Public Health: Review Article. The Sci.World. J. 1(1):1-13.

12. Percival, Steven, Chalmers, Rachel, Embrey, Martha, Hunter, Paul, Sellwood, Jane and Wyn-Jones, Peter. (2004). Microbiology of Waterborne Diseases. Elsevier Ltd. p 480.

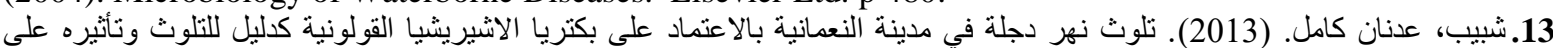

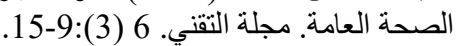

14. Armisen, T. Garcia, Nceoglu, Ozgul, Ouattara, Nouho Koffi, Anzil, Adriana, Verbanck, Natacha Brion and Servais, Pierre. (2014). Seasonal Variations and Resilience of Bacterial Communities in Sewage Polluted Urban River. Pols One Org. 9(3): 1-13.

15. Ghenghesh, K. Sifaw, Ahmed, Salwa, F., El-Khalek, Rania, Abdel, Al-Gendy, Atef and Klena, John. (2007). Aeromonas-Associated Infections in Developing Countries: Review Article. J. Infect Dev. Countr., 2(2): 81-98.

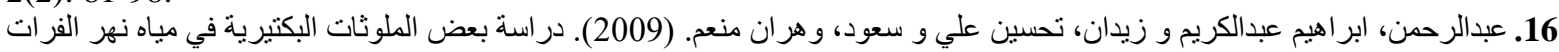

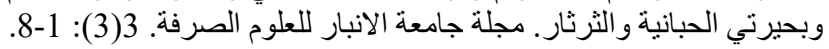

17. Silby, M.W.,Winstanley, C., Godfrey Scott, A.C., Levy, Stuart B. and Jackson, Robert W. (2011). Pseudomonas Genomes: Diverse and Adaptable: Review Article. Federation of European Microbiological Societies, Microbiol Blackwell Publishing Ltd. Rev 35: pp 652-680.

18. Gaalova, B., Donauerova, A., Seman, M. and Bujdakova, H. (2014). Identification and ß-lactam Resistance in Aquatic Isolates of Domica Cave in Solvak Karst (Solvakia). Int. J. of Speleol. 43(1): 69-77.

19. Riggio, Marcello P., Lennon, Alan, Taylor, David J. and Bennett. (2011). Molecular Identification of Bacteria Associated with Canine Periodontal Disease. Vet. Microbiol. 150: 394-400.

20. Akhter, A., Imran, M. and Akhter. (2015). Prevalence of Multi-Drug Resistance and Health Risk Potential in Metal Tolerant Enterobacter spp. from Polluted River Water. Eur. J. Environ. Ecol. 2(1): 44-52.

21. Pitt, T.L., Malnick, H, Shah, J., Chattaway, M.A., Keys, C.J., Cooke, F.J. and Shah, H.N. (2007). Characterisation of Exiguobacterium aurantiacum Isolates from Blood Cultures of Six Patients. J. Compil. Euro. Soci. of Clin. Microbiol. and Infect. Dis. 13(1): 937-948.

22. Paul, Dipak and Sinha, S. Narayan. (2015). Isolation an Characterization of a Phosphate Solubilizing Heavy Metal Tolerant Bacterium from River Ganga, West Bengal, India: Original Article. Songklanakarin J. Sci. Technol. 37 (6): 657. 